\title{
Resins from Formaldehyde. CIV. Hydroxymethylation of Diisopropyl Ketone with Formaldehyde*
}

\author{
Tatsuro Ouchi, Yoshitaka ARIta, and Minoru Imoto \\ Department of Applied Chemistry, Faculty of Engineering, \\ Kansai University, Senriyama, Suita, 565, Japan.
}

(Received March 2, 1976)

\begin{abstract}
KEY WORDS Hydroxymethylation / Diisopropyl Ketone / Formaldehyde / 2,2,4-Trimethyl-1-pentanol-3-one / Kinetic Equation / Six-Number Rule /
\end{abstract}

In order to prepare a novel kind of photodegradable thermoplastic resin, a study about the introduction of a methylol group into 2,4dimethyl-3-pentanone(I, diisopropyl ketone, DIPK) was made.<smiles>CC(C)C(=O)C(C)C</smiles>

DIPK, I
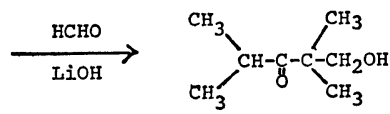

II
The desired 2,2,4-trimethyl-1-pentanol-3-one (II) can be easily prepared by the reaction of DIPK with formaldehyde(F) in an alkaline aqueous medium. When lithium hydroxide was used as a catalyst, the following kinetic equation was obtained

$$
\text { Rate }=-\mathrm{d}[\mathrm{F}] / \mathrm{d} t=k[\mathrm{~F}][\mathrm{DIPK}][\mathrm{LiOH}]
$$

Further reaction of $F$ with II gave 2,2,4trimethyl-1,3-pentanediol (III) instead of the expected 2,2,4,4-tetramethyl-1,5-pentanediol-3one (IV).

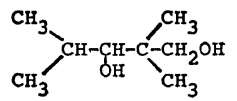

III

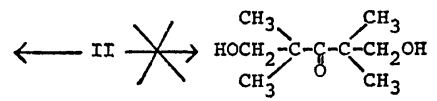

IV
The preparation of II was briefly described by Decombe $^{2}$ in 1936 , using the same procedure as the present paper. But the preparative method of the compound III by the reaction of II and

\footnotetext{
* For Part 103 of this series, see ref 1.
}

F seems to be novel. In 1927, III was prepared from isobutyraldehyde by Krestinski, et $a l .^{3}$

\section{EXPERIMENTAL}

Diisopropyl ketone(DIPK) was of highly pure commercial grade. Formaldehyde $(F)$ was applied as commercial $37-\%$ water solution, containing about $10-\%$ methanol.

\section{Procedures for kinetic study}

A $100-\mathrm{cm}^{3}$ three-necked flask equipped with a reflux condenser, a stirrer, and a thermometer was adjusted at $50^{\circ} \mathrm{C}$. Twenty-five $\mathrm{cm}^{3}$ of methanolic solution containing DIPK, $25 \mathrm{~cm}^{3}$ of aqueous solution of $37-\% \mathrm{~F}$, and $3 \mathrm{~cm}^{3}$ of aqueous solution of lithium hydroxide were mixed and diluted with methanol up to $60 \mathrm{~cm}^{3}$ in order to let the mixture become homogeneous. This reaction mixture was placed into the flask mentioned above. At each fixed time, $5 \mathrm{~cm}^{3}$ of an aliquot was pipetted out and the concentration of formaldehyde was determined by the sodium sulfite method. Plotting the quantities of consumed formaldehyde vs. reaction time gave a straight line. The slope of the line represents the reaction rate of DIPK with F.

Preparation of 2,2,4-trimethyl-1-pentanol-3-one(II)

A homogeneous reaction system was obtained by mixing $36 \mathrm{~cm}^{3}$ of $37-\% \mathrm{~F}, 17.3 \mathrm{~g}$ of DIPK, $25 \mathrm{~cm}^{3}$ of $1-N \mathrm{LiOH}, 250 \mathrm{~cm}^{3}$ of water, and 137 $\mathrm{cm}^{3}$ of methanol. This solution was refluxed for $24 \mathrm{hr}$. After distilling off most of the methanol, the remained product was extracted with benzene. The benzene layer was washed with diluted 
sulfuric acid and water and distilled in vacuo. The compound II was obtained in a yield of $15.4 \mathrm{~g}(70.5 \%) ;$ bp $96.5-98^{\circ} \mathrm{C} / 20 \mathrm{mmHg}$ (lit. ${ }^{2}$ 97-98 $\left.{ }^{\circ} \mathrm{C} / 20 \mathrm{mmHg}\right), n_{\mathrm{D}}^{25} 1.4379, d^{25} 0.9565$; IR $(\mathrm{NaCl}) 3470 \mathrm{~cm}^{-1}$, ( $\left.\nu_{\mathrm{OH}}\right) 1700 \mathrm{~cm}^{-1}\left(\nu_{\mathrm{C}=0}\right)$.

Preparation of 2,2,4-trimethyl-1,3-pentandiol (III)

To a homogeneous solution, which was prepared by heating a mixture of $20.0 \mathrm{~g}$ of paraformaldehyde, $100 \mathrm{~cm}^{3}$ of water, and $70 \mathrm{~cm}^{3}$ of methanol, $25.0 \mathrm{~g}$ of II and $64 \mathrm{~cm}^{3}$ of $1-N$ LiOH were added. This mixture was refluxed for $48 \mathrm{hr}$. After distilling off the methanol, the reaction mixture was extracted with benzene. From the benzene extract, the compound III was isolated by distillation, bp $112-113^{\circ} \mathrm{C} / 10$ mmHg. After recrystallization from $n$-hexane, it became a colorless table crystal; Yield $3.93 \mathrm{~g}$ (15.5\%), mp 51.5-52.2 ${ }^{\circ} \mathrm{C}$ (lit. ${ }^{3} 52^{\circ} \mathrm{C}$ ). IR $(\mathrm{KBr})$ gave no signal of $\nu_{\mathrm{C}=\mathrm{O}}$ at $1700 \mathrm{~cm}^{-1}$. ${ }^{13} \mathrm{C} \mathrm{NMR}^{*}$ $\left(\mathrm{CDCl}_{3}\right) \delta 82.8\left(\mathrm{~d}, \mathrm{C}^{\mathrm{c}}\right), 72.9\left(\mathrm{t}, \mathrm{C}^{\mathrm{a}}\right), 39.1\left(\mathrm{~s}, \mathrm{C}^{\mathrm{b}}\right)$, $29.2\left(\mathrm{~d}, \mathrm{C}^{\mathrm{d}}\right), 23.4\left(\mathrm{q}, \mathrm{C}^{\mathrm{g}}, \mathrm{C}^{\mathrm{h}}\right), 19.9$ and $16.8 \mathrm{ppm}$ $\left(\mathrm{q}, \mathrm{C}^{\mathrm{e}}\right.$ or $\left.\mathrm{q}, \mathrm{C}^{\mathrm{f}}\right)$; mass spectrum $m / e 146\left(\mathrm{M}^{+}\right)$. Anal. Calcd for $\mathrm{C}_{8} \mathrm{H}_{18} \mathrm{O}_{2}: \mathrm{C}, 65.67 ; \mathrm{H}, 12.43$. Found: C, 65.52; H, 12.85. Mol wt 146.

\section{RESULTS AND DISCUSSION}

\section{Effects of the Concentration of Reagents}

Figure 1 shows the effects of [DIPK], [F], and $[\mathrm{LiOH}]$ on the rate of reaction. From this figure, it was concluded that the rate of reaction could be expressed by the following equation.

$$
R=\frac{-\mathrm{d}[\mathrm{F}]}{\mathrm{d} t}=k[\mathrm{~F}][\mathrm{DIPK}][\mathrm{LiOH}]
$$

Comparison between the Rates of Reactions of Formaldehyde with DIPK and with 2,2,4Trimethyl-1-pentanol-3-one

The results are shown in Figure 2. The conditions for reaction were the same as those mentioned above. The "prepared formaline" described in Figure 2 means an aqueous formaldehyde solution which was prepared by boiling paraformaldehyde in distilled water. From these two lines the values of $k$ were

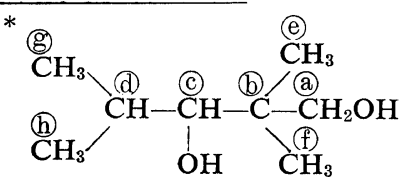

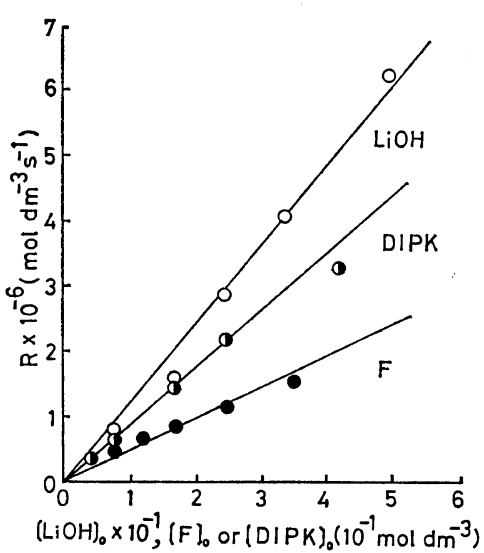

Figure 1. $-\mathrm{d}[\mathrm{F}] / \mathrm{d} t$ vs. $[\mathrm{DIPK}]_{0},[\mathrm{~F}]_{0}$, and $[\mathrm{LiOH}]_{0}$ at $50^{\circ} \mathrm{C}: \bigcirc,[\mathrm{DIPK}]_{0}=0.17 \mathrm{~mol} \mathrm{dm}^{-3},[\mathrm{~F}]_{0}=0.17$ $\mathrm{mol} \mathrm{dm}-3, \quad[\mathrm{LiOH}]_{0}$ varied; $[\mathrm{F}]_{0}=0.17 \mathrm{~mol} \mathrm{dm}^{-3}, \quad[\mathrm{LiOH}]_{0}=8 \times 10^{-3} \mathrm{~mol} \mathrm{dm}^{-3}$; , $[\mathrm{DIPK}]_{0}=0.17 \mathrm{~mol} \mathrm{dm}^{-3},[\mathrm{~F}]_{0}$ varied, $[\mathrm{LiOH}]_{0}=$ $8 \times 10^{-3} \mathrm{~mol} \mathrm{dm}^{-3}$.

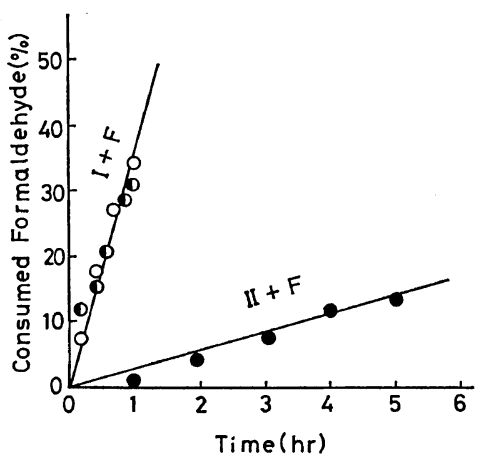

Figure 2. Rate of reaction of $\mathbf{I}$ and $\mathbf{I I}$ with $\mathbf{F}$ at $50^{\circ} \mathrm{C}:[\mathrm{F}]_{0}=0.17 \mathrm{~mol} \mathrm{dm}^{-3} ;[\mathrm{LiOH}]_{0}=0.12 \mathrm{~mol} \mathrm{dm}^{-3}$; $[\mathbf{I}]_{0}=[\mathbf{I I}]_{0}=0.17 \mathrm{~mol} \mathrm{dm}^{-3} ; \bigcirc$, $\mathrm{O}$, commercial formaline; $\boldsymbol{D}$, prepared formaline.

Table I. Rate constants at $50^{\circ} \mathrm{C}$

\begin{tabular}{cc}
\hline Substance & $k$ \\
\cline { 2 - 2 } & $\mathrm{dm}^{6} \mathrm{~mol}^{-2} \mathrm{~s}^{-1}$ \\
\hline I & $5.04 \times 10^{-3}$ \\
II & $0.37 \times 10^{-3}$ \\
\hline
\end{tabular}

calculated according to eq 1 and are listed in Table I. As in the case of the reaction of II with $F$, eq 1 was assumed to be applicable.

It is very interesting that the rate of DIPK was 14 times faster than that of 2,2,4-trimethyl-1pentanol-3-one. However, the activation energies 
Formaldehyde Resins. CIV.

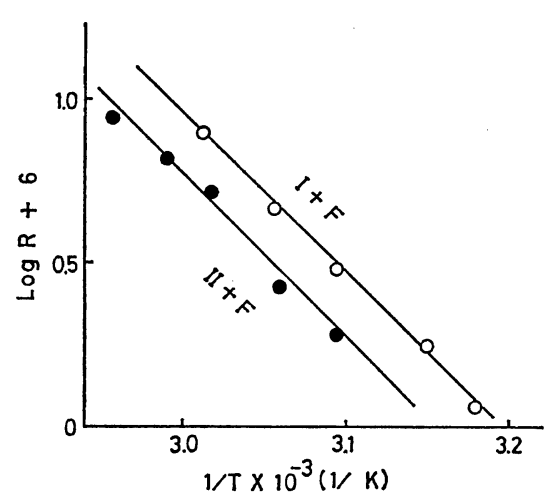

Figure 3. Determinations of activation energy at $41-65^{\circ} \mathrm{C} . \quad[\mathrm{I}]_{0}=[\mathbf{I I}]_{0}=0.17 \mathrm{~mol} \mathrm{dm}^{-3} ;[\mathrm{F}]_{0}=0.17$ $\mathrm{mol} \mathrm{dm}-3 ; \quad[\mathrm{LiOH}]_{0}=2.5 \times 10^{-2} \mathrm{~mol} \mathrm{dm}^{-3}(\mathbf{I}), \quad 0.17$ $\mathrm{mol} \mathrm{dm}-3(\mathbf{I I})$.

Table II. Activation energy and Arrhenius preconstant

\begin{tabular}{cccc}
\hline \multirow{2}{*}{ Substance } & $E$ & & $A$ \\
\cline { 2 - 2 } & $\mathrm{kJ} \mathrm{mol}^{-1}$ & & $\mathrm{dm}^{6} \mathrm{~mol}^{-2} \mathrm{~s}^{-1}$ \\
\hline I & 93.7 & & $7.03 \times 10^{12}$ \\
II & 95.8 & & $1.12 \times 10^{12}$ \\
\hline
\end{tabular}

of the reactions in both cases were almost the same, as shown in Figure 3 and Table II.

Accordingly, the large difference between the rate constants of DIPK and 2,2,4-trimethyl-1pentanol-3-one was due to the difference of entropy terms.
The reason why the compound IV could not be prepared may be explained by the following formula of $\mathbf{V}$.<smiles>CC1(C)[C+]OCC(C)(C)C1=O</smiles>

In such a case, the reactive hydrogen $\left(\mathbf{H}^{*}\right)$ makes a six-membered ring intramolecularly with the introduced $\mathrm{OH}$ group. According to the "sixnumber rule,", the substitution reaction at $\mathrm{C}$ $\mathrm{H}^{*}$ in the above structure is deemed quite difficult. Thus a crossed Cannizzaro's reaction takes place between the $\mathrm{C}=\mathrm{O}$ group and $\mathrm{F}$ to give 2,2,4-trimethyl-1,3-pentandiol(III).

\section{REFERENCES}

1. T. Ouchi, S. Otsuka, and M. Imoto, Bull. Chem. Soc. Japan, 48, 918 (1975).

2. J. Decombe, Comptes rendus, 203, 1077 (1936).

3. W. Krestinski and F. Ssolodki, Ber., 60, 1872 (1927).

4. M.S. Newman, "Steric Effects in Org. Chemistry," John Wiley and Sons, Inc., New York, N.Y., 1956, p 206. 